\title{
A tribute to the late Professor Donald Simpson, Australian neurosurgeon and namesake of the Simpson grading system for meningioma extent of resection
}

\author{
Michael R. Chicoine, MD, Alexander T. Yahanda, MS, and Ralph G. Dacey Jr., MD \\ Department of Neurological Surgery, Washington University School of Medicine, St. Louis, Missouri
}

\begin{abstract}
Donald Simpson (1927-2018) was a neurosurgeon from Adelaide, Australia, who is often cited for the 1957 publication he wrote as a trainee on the relationship between extent of resection and outcomes for meningiomas. That paper summarized a series of over 300 patients operated on in England by well-known neurosurgeons Sir Hugh Cairns and Joseph Buford Pennybacker. Simpson was also known later in his career, when he was at the University of Adelaide in South Australia, for his contributions to the areas of hydrocephalus, spina bifida, craniofacial anomalies, head injury, brain abscesses, and neurosurgical history, and he published extensively on these topics. In addition to his work in clinical neurosurgery, Simpson made humanitarian contributions studying kuru in New Guinea and aiding refugees during the Vietnam War. Simpson was an active member and leader of many Australian surgical organizations and was an officer of the Order of Australia. Donald Simpson's legacy as an adult and pediatric neurosurgeon, an academician, a leader, and a humanitarian is extensive and will prove long lasting. Professor Simpson's life serves as an example from which all neurosurgeons may learn.
\end{abstract}

https://thejns.org/doi/abs/10.3171/2020.6.JNS201331

KEYWORDS Australia; Donald Simpson; meningioma; Simpson grading; history

$\mathrm{M}$ OST contemporary neurosurgeons who treat brain tumors are familiar with the Simpson grading system for assessing the extent of resection of intracranial meningiomas. The Simpson grade is derived from a 1957 publication in which Dr. Donald Simpson (Fig. 1) summarized a large series of meningioma cases from Oxford and London, England. His paper demonstrated that the extent of surgical resection impacted the potential for future meningioma recurrence or progression. ${ }^{1}$ Since 1957, this study has been cited over 2200 times (per Google Scholar), placing it on par with other notable neurosurgical publications such as the 1986 Spetzler-Martin arteriovenous malformation grading system ${ }^{2}$ (cited over 2200 times) and the 1980 Fisher grading of subarachnoid hemorrhage $^{3}$ (cited over 3400 times). However, Professor Simpson lived an extraordinary life that was defined by much more than his most well-known paper. In this article, the authors detail the life of Donald Simpson so that all neurosurgeons may learn from his example.

\section{Simpson's Early Life}

Donald Simpson was born on April 8, 1927, in Ade- laide, Australia, the youngest child of Allen Simpson and Janet Simpson (née Hubbe). His family members included influential industrialists in South Australia. His father had been a director of the Bank of Adelaide and the South Australian Gas Company, was a member of the Royal Geographical Society of Australasia, had served as mayor of Adelaide, and was awarded the King Albert Medal by the king of Belgium in 1919 for humanitarian service in assisting Belgian relief efforts after World War I. ${ }^{4}$ Unfortunately, when Simpson was 12 years old, his father died after suffering aphasia and paralysis from a stroke. ${ }^{5,6}$ Perhaps this tragic event sparked Simpson's future career interests in neurology and neurosurgery.

During his studies, Simpson was accomplished not only in medicine, but also broadly in academics, and before heading to medical school he won the Tennyson Medal for English (awarded to the best English student in South Australia). ${ }^{7}$ Simpson completed his medical training at the University of Adelaide, during which time he met prominent neurosurgeon and fellow South Australian Sir Hugh Bell Cairns (1896-1952) (Fig. 2) while Cairns was visiting his homeland. During that visit, Cairns extended to Simpson an invitation to become Cairns' trainee in 


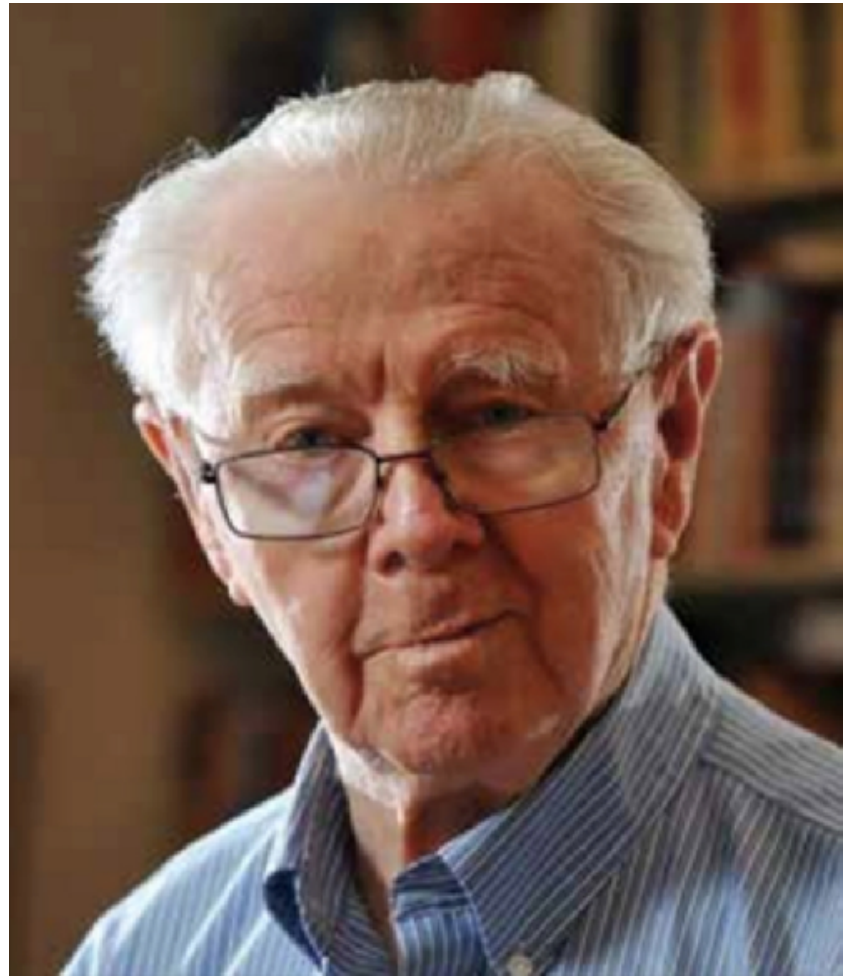

FIG. 1. Donald Simpson in 2015 at 87 years of age. Image previously published by the Australian Medical Association (South Australia). Used with permission. Figure is available in color online only.

neurosurgery at Oxford University after medical school. Simpson accepted this offer, and moved to Oxford, England, in 1951.? His first projects at Oxford included works in neuroanatomy with Professor Sir W. E. LeGros Clark. In 1953, Simpson began his neurosurgical training at the Radcliffe Infirmary Oxford under Mr. Joseph Buford Pennybacker (1907-1983) (Fig. 3). Cairns had passed away in

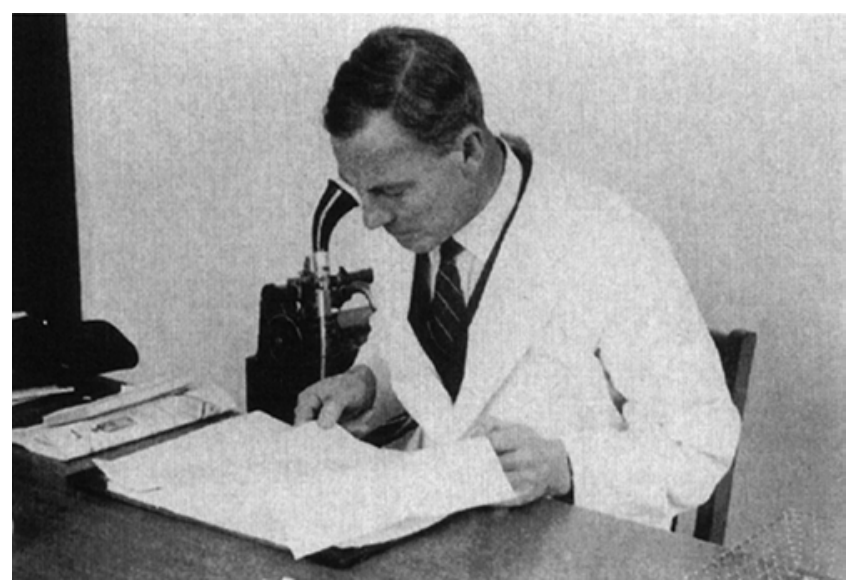

FIG. 2. Neurosurgeon Sir Hugh Bell Cairns (1896-1952), a native of South Australia. Cairns invited Donald Simpson to train in neurosurgery at Oxford after Simpson's medical training at the University of Adelaide. Used with permission of the Department of Neurosurgery, John Radcliffe Hospital.

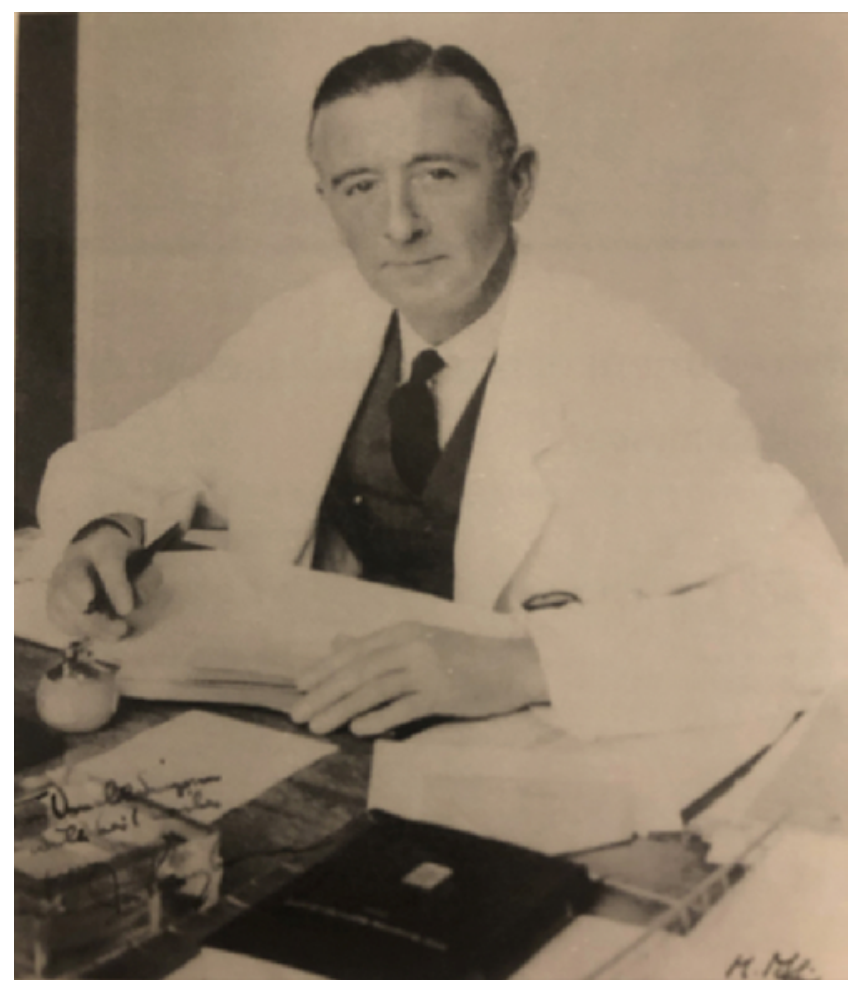

FIG. 3. Neurosurgeon Joseph Buford Pennybacker (1907-1983), who honored Hugh Cairns' promise to train Donald Simpson at Oxford after Cairns' death. Used with permission of the Department of Neurosurgery, John Radcliffe Hospital. Figure is available in color online only.

1952, but Pennybacker honored Cairns' promise to train Simpson.

The offer Simpson had received from Cairns (Fig. 2) was extraordinary, as Cairns was a leading figure in neurosurgery at the time. Cairns had trained many other future leaders of neurosurgery, including Professor Krayenbuhl, who later became Professor Gazi Yașargil's chairman in Zurich, Switzerland. Cairns himself had learned directly from Dr. Harvey Cushing, having spent time with Cushing as his assistant at the Brigham Hospital in Boston from 1926 to $1927,8,9$ and Cairns later established the first neurosurgical unit in a teaching hospital in England after becoming head of the Department of Neurosurgery at the London Hospital. ${ }^{10}$ Apart from helping establish the field of neurosurgery in England and educating generations of future neurosurgeons, Cairns helped to establish the Combined Services Hospital for Head Injuries at St. Hugh's Hospital. During World War II, more than 13,000 patients with head injuries were treated at this specialized hospital, which spurred the creation of mobile neurosurgical units used by the Royal Army Medical Corps during World War II and then militaries from multiple nations in the Vietnam War. ${ }^{11}$ Cairns also designed a new type of motorcycle helmet that greatly reduced the number of serious head injuries and deaths from accidents. ${ }^{12,13}$ Cairns achieved the rank of brigadier in the English army and was knighted in $1946.9,14,15$

Simpson began his training in England in 1952, and at that time also married Joanna Erlistoun Thomson of 
Adelaide. Joanna had met Simpson while attending college at the University of Adelaide. She subsequently had served as a diplomatic cadet and spent time in Ottawa, Canada, in the office of the Australian High Commissioner to Canada. After marrying Simpson, Joanna resigned from her job as a diplomatic cadet and began working on a novel, Treason of the Clerks, which was published posthumously. ${ }^{16}$ In 1956, Simpson and his wife returned from Oxford to Adelaide, at which time Simpson joined neurosurgeon Trevor "Jim" Dinning (1919-2003) (Fig. 4) at the Royal Adelaide Hospital. Dinning would ultimately become a close colleague, mentor, and friend to Simpson, and Simpson is credited with coining the term "Dinning's Law": "There is no operation that wouldn't be better performed by a neurosurgeon." ${ }^{5}$

\section{The Simpson Grading System}

It is of interest to reflect specifically on the 1957 publication that established the Simpson classification. ${ }^{1}$ In this seminal work, Simpson summarized outcomes for 339 meningioma patients, including 242 from Oxford and 97 from London. He categorized these patients in great detail by their anatomical location and their clinical outcomes and subsequent tumor progression. This led to the development of a 5-tier grading system for the extent of resection. Grade I included macroscopically complete removal of tumor with excision of its dural attachments and any abnormal bone, including resection of venous sinuses if involved. Grade II included macroscopically complete removal of tumor and its visible extension, with coagulation of its dural attachment. Grade III included macroscopically complete removal of intradural tumor without resection or coagulation of the dural attachment or its extradural extensions. Grade IV included partial tumor removal, leaving intradural tumor in situ. Grade V included simple decompression with or without biopsy.

Simpson concluded that patients with a grade I level of resection had an $8.9 \%$ risk of recurrence during follow-up, whereas grade $\mathrm{V}$ patients had a $78 \%$ risk of recurrence or progression. Some of the patients in this series had been followed as long as 17 years-a notable accomplishment prior to the advent of the electronic medical record. Also noteworthy is that this investigation was based purely on detailed clinical assessments, as it was completed before the advent of modern imaging methods such as CT or MRI. Moreover, this remarkable and extensive body of work, which involved a series of patients that had been operated on by Cairns, Pennybacker, and colleagues from 1938 to 1954, had Simpson as the sole author.' This may have been more commonplace at that time, but in today's academic environment it would no doubt be considered unusual.

Simpson's 1957 paper has been cited extensively over the years (cited 1373 times per Web of Science and more than 2200 times per Google Scholar) and currently has an $\mathrm{H}$-index of 97. It is among the most heavily cited papers in all of neurosurgery ${ }^{17,18}$ and is the most cited article about meningiomas. ${ }^{19}$ Indeed, the dogma of maximal safe resection of intracranial meningiomas remains a guiding strategy for neurosurgeons. However, some have questioned

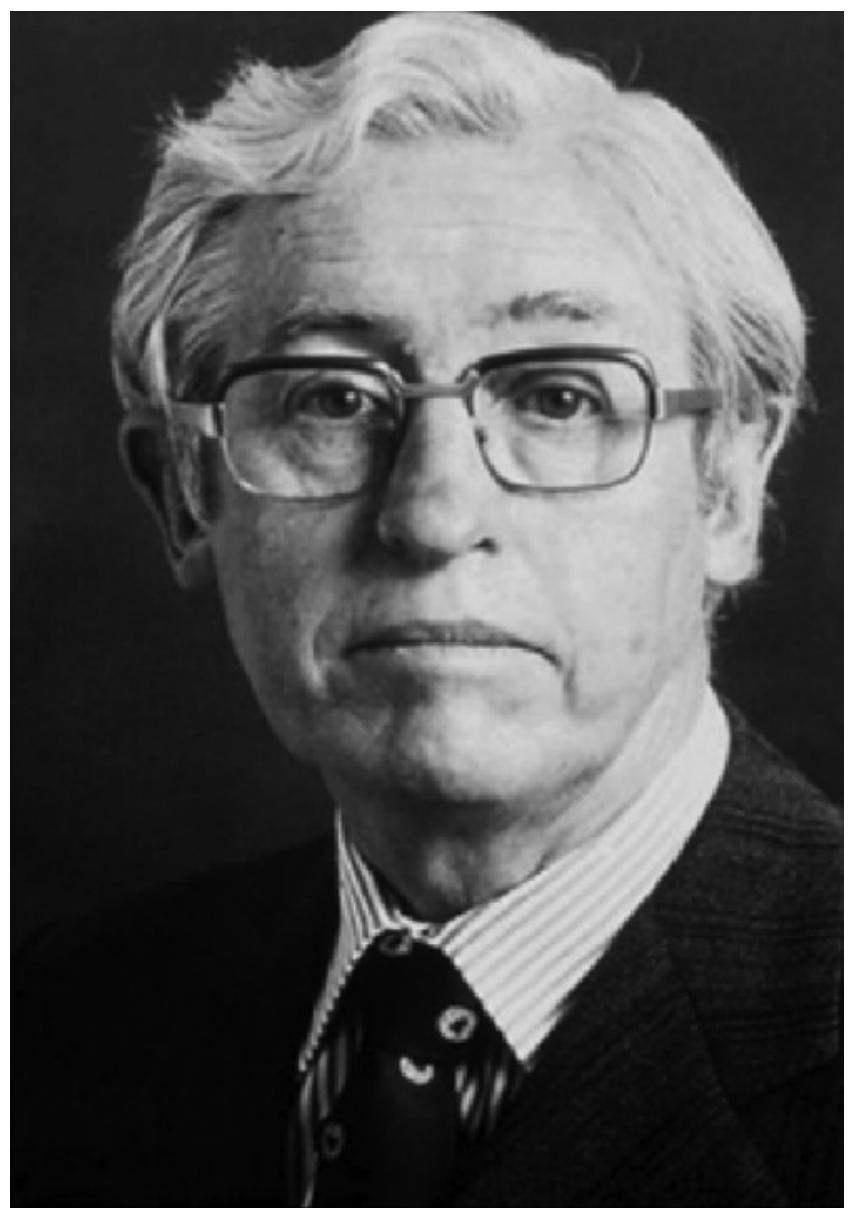

FIG. 4. Neurosurgeon Trevor "Jim" Dinning (1919-2003), a neurosurgeon at the Royal Adelaide Hospital. Dinning was a close friend, colleague, and mentor to Simpson. Used with permission of the Department of Neurosurgery, Royal Adelaide Hospital.

whether the conclusions drawn in Simpson's paper still hold true today in the modern era of neurosurgery. For example, Sughrue and colleagues at the University of California, San Francisco published a study in 2010 detailing how patients with Simpson grade I, II, and III meningioma resections all had similar rates of tumor recurrence. ${ }^{20}$ One limitation of this study was that the median follow-up was only 3.7 years. Another paper, published in 2017 by Nanda and colleagues from Louisiana State University in Shreveport, examined a series of over 450 patients and demonstrated that Simpson grading was still a predictor of recurrence rates for patients undergoing surgical resection for WHO grade I meningiomas. ${ }^{21}$ Al-Mefty and colleagues have generally advocated aggressive resection of meningiomas, and in fact coined the concept of a "Simpson grade zero" resection-for which a $2-\mathrm{cm}$ margin of dura is resected in addition to the dural attachment of the tumor-to further reduce the potential for residual and/or recurrent tumor. ${ }^{22}$

Impressively, more than 60 years after its initial publication, Simpson's work as a young trainee still holds significant merit in the field of neurosurgery. Simpson mentioned in the original publication and in later com- 
munications that the extent of resection was not the only variable to impact the risk of meningioma recurrence. In the 1957 publication, ${ }^{1}$ he stated: "But whether in practice clinical recurrences are more likely to result from the intrinsic malignancy of the tumours, rather than from the inadequacy of the surgical resections, is still disputable." These comments foreshadow the current understanding of meningioma biology, the WHO categorization of meningiomas, and the more recent molecular characterizations of meningiomas. ${ }^{23-25}$ We now know that in addition to the Simpson grade of meningioma resection, the underlying WHO grade, molecular features, and other therapeutic interventions such as radiation also can impact subsequent tumor progression. ${ }^{24-27}$

\section{Simpson's Other Accomplishments}

Professor Simpson had many other great accomplishments in neurosurgery (see Supplemental Document 1 for his curriculum vitae and Supplemental Document 2 for a bibliography of all his publications). In 1957, Simpson spent time in New Guinea as a member of a University of Adelaide group investigating kuru, a progressive neurodegenerative disorder common at that time among the Fore people. ${ }^{28,29} \mathrm{He}$ later revisited New Guinea in 1959 and developed a close relationship with D. Carleton Gajdusek, who was later awarded the Nobel Prize for Physiology for his work on prion disease. ${ }^{30}$ In 1960, with Jim Dinning (Fig. 4), Simpson implanted the first ventriculoperitoneal shunts in South Australia and worked extensively on the links between folic acid deficiency and neural tube defects. ${ }^{31,32}$ From 1972 to 1973 , during the Vietnam War, Simpson spent time at Cho Ray Hospital in Saigon. His international service continued after the war's end as he became the first president of the Indochina Refugee Association (later known as the Australian Refugee Association), which was established in 1975 to help Vietnamese families settle in South Australia. ${ }^{7,30}$

Among his many accolades, Simpson became a member of the Neurosurgical Society of Australasia (NSA) in 1964. He served as the NSA secretary from 1969 to 1973 , president from 1973 to 1975 , and later the curator of the NSA Museum of Surgical Instruments. He was a member of the Royal Australasian College of Surgeons, chairman of its surgical board from 1975 to 1982, a member of its court of examiners from 1977 to 1986, a member of its National Road Trauma Committee beginning in 1986, and convener and foundation member of its section of the History of Surgery and Anesthesia (now known as the Section of Surgical History) beginning in 1987. Simpson was also a foundation fellow of the Australasian College of Rehabilitation Medicine. He was the NSA Honored Guest and Lecturer in 1997 and the Jamieson Mendelson Lecturer in 2003. He won the Royal Australasian College of Surgeons Medal of Service in 1988 and the Award for Excellence in Surgery in 2002, and he was the inaugural winner of the Sir Henry Newland Award in 2013. Simpson became a member of the International Society for Pediatric Neurosurgery in 1973, serving as president from 1985 to 1986. He became a member of the Society for Research into Hydrocephalus and Spina Bifida in 1970, was a life mem- ber and patron of the Spina Bifida Association of South Australia, and served as chairman of the South Australian Executive Committee of the Australian Brain Foundation until 1985. He was awarded the President's Service Award from the Australian Council for Rehabilitation of the Disabled in $1984{ }^{7,30}$ Simpson coauthored and was coeditor of two books, and the author or coauthor of more than 165 publications and several book chapters.

During his prestigious career, Simpson worked at all of Adelaide's major hospitals. His clinical appointment was at the University of Adelaide. He was the director of Pediatric Neurosurgery at Adelaide Children's Hospital beginning in 1970, and he worked to improve surgical access for other hospitals in Australia, including rural hospitals. Beginning in 1985, Simpson also devoted much of his emphasis to head injury research, joining the Road Accident Research Unit of the Australian NHMRC (National Health and Medical Research Council) as a senior research associate, and he became a strong campaigner for bicycle helmets. ${ }^{33}$ Simpson was a member of the Order of Australia (AM), beginning in 1980 for his service to handicapped children, and later he was named officer of the Order of Australia (AO) in 2004 for service to the medical fields of neurosurgery and neurotrauma as a researcher and academician. He received an honorary doctorate from the University of Adelaide in $1985 .{ }^{34}$

After a long, illustrious career, Professor Simpson died on May 22, 2018, at 91 years of age. Notably, he continued to publish nearly until the end of his life, with his last publications coming in 2013..$^{35,36}$ Simpson was survived by his children, Jane, Matthew, and Kate, and four grandchildren. $\mathrm{He}$ is held in great esteem as a neurosurgeon and pioneer of neurosurgery in South Australia and throughout South Australasia. Simpson's contributions to neurosurgery in South Australia and globally were extensive and remain long lasting.

\section{Development of a Personal Connection}

The impetus for the current article began in 2013 when one of this paper's authors (Michael Chicoine) was preparing a review presentation on meningiomas. While performing a literature search with regard to Professor Simpson's 1957 publication, he came upon other neurosurgical publications by a Donald Simpson from 2012 to $2013 .{ }^{35-37}$ As Simpson's publication on meningiomas was nearly 60 years old, it was not clear whether these current publications were from the same author. There was an email address listed with these 2013 publications, to which Chicoine sent the following email:

Professor Simpson - I read with great interest your paper "Neurosurgery in the Age of Cushing: The Achievement of Leonard Lindon (Simpson 2012)." Please pardon me if I am incorrect, but I understand you left Adelaide for a period of time to study neurosurgery at the Radcliffe Infirmary at Oxford, where you reviewed the meningioma records of Cairns and colleagues to establish the 'Simpson grade' that we use to this day. Is my understanding of history correct? If you would be so gracious, I would very much enjoy if you could email a picture of you. Sincerely, Michael Chicoine

This email was sent with considerable uncertainty as to whether this was the appropriate Donald Simpson or 


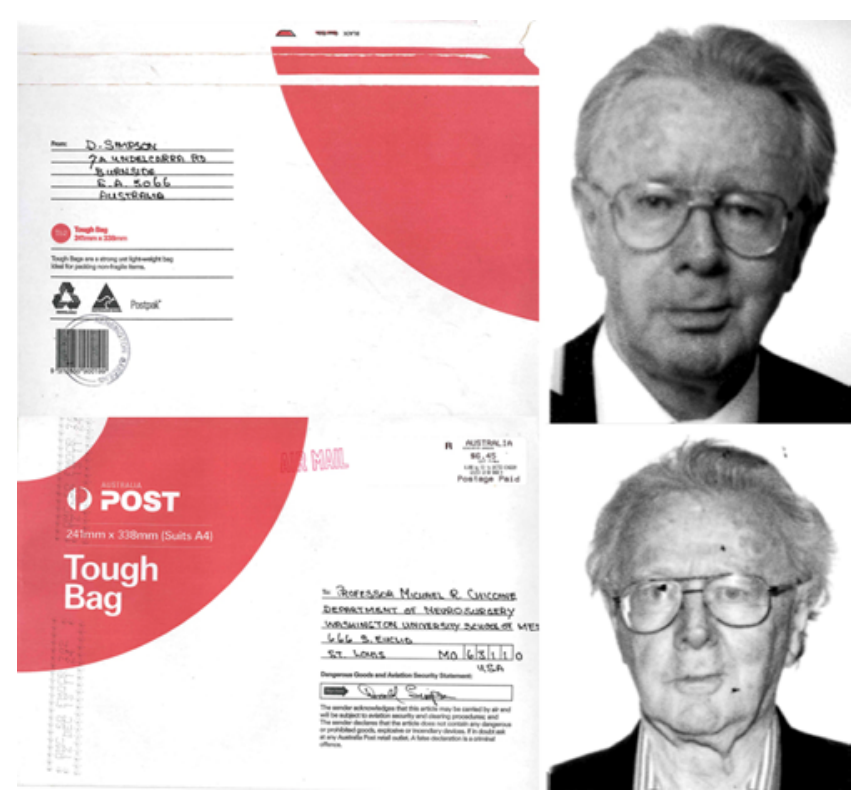

FIG. 5. Images of a package prepared and signed by Donald Simpson on December 12, 2013, in Australia and mailed to Michael Chicoine in St. Louis, Missouri (left). The package included two older passport photos of Simpson (right), and three reprints of articles that Simpson had published in 2012 and 2013. Figure is available in color online only.

whether the Professor Simpson of the Simpson grade was even still alive. Nevertheless, much to Chicoine's surprise, an extensive reply from Simpson arrived mere hours later:

Dear Professor Chicoine - You are correct. I am a South Australian graduate of the University of Adelaide; when I was a medical student there in 1948 I met Sir Hugh Cairns, who saw some work of mine and offered me training in neurosurgery when I graduated and had obtained a general surgical qualification. Cairns died in 1952 but his successor, J. B. Pennybacker, honoured this promise and I trained under this great neurosurgeon. I owe my career to this kind and stimulating man who assigned the recurrence of meningiomas to me as a subject for study. I was with him from 1953-6, and again in 1962, when I reviewed my earlier study as a thesis; I did not publish anything from this second consideration, which seemed to confirm the first study. I think my chief regret is my failure to recognize the nature of what are now called hemangiopericytomas: I did recognize their propensity to recur, but I called them 'undifferentiated meningiomas'. My later career was chiefly in Paediatric Neurosurgery. I am now a very old man, and I have not been photographed for some time: Also, I do not have scanning facilities on my computer. I can offer you a 2007 passport photograph, and if you wish I will send this to your hospital address. Thank you for your interest. DONALD SIMPSON.

This reply sparked a series of periodic emails over the years between Chicoine and Simpson. As an additional surprise, within a couple of weeks of the initial email communication, a package from Adelaide, Australia, arrived at Chicoine's desk in the Department of Neurosurgery at Washington University in St. Louis. This package was dated December 12, 2013, and had been hand-addressed and signed by Donald Simpson himself (Fig. 5). It contained passport photos as promised and three reprints (Fig. 6) of articles that Professor Simpson had published in 2012 and
REVIEW ARTICLE

\section{Neurosurgery in the age of Cushing: the achievement of Leonard Lindon \\ Donald Simpson

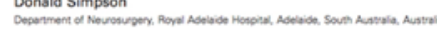
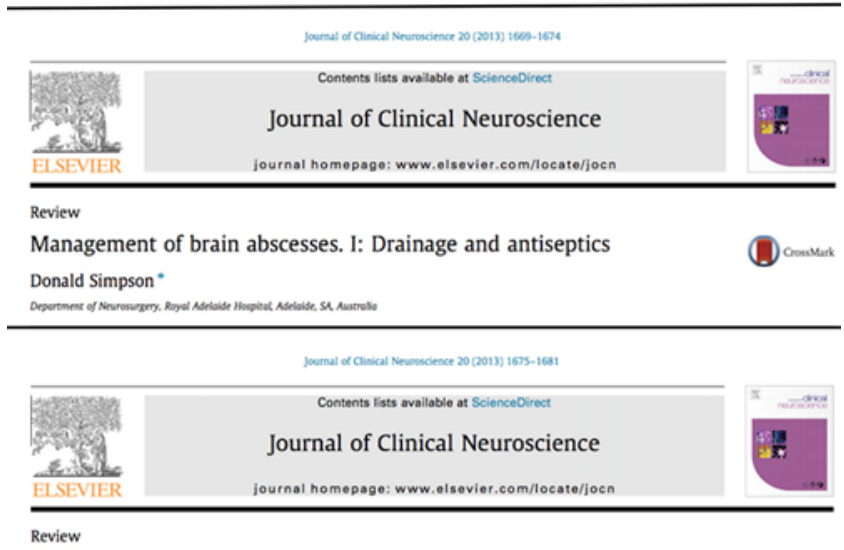

Management of brain abscesses. II: Antibiotics and computed tomography Donald Simpson*

FIG. 6. First pages of the three reprints that Donald Simpson sent to Michael Chicoine in December of 2013. Simpson D. Neurosurgery in the age of Cushing: the achievement of Leonard Lindon. ANZ J Surg. 2012;82(5):311-317, (c 2012 John Wiley and Sons; Simpson D. Management of brain abscesses. I: Drainage and antiseptics. J Clin Neurosci. 2013;20(12):1669-1674, @ 2013 Elsevier; and Simpson D. Management of brain abscesses. II: Antibiotics and computed tomography. J Clin Neurosci. 2013;20(12):1675-1681, ( 2013 Elsevier. Images used with permission of the publishers. Figure is available in color online only.

2013, including a two-part series on the management of brain abscesses and a review article about neurosurgeon Leonard Lindon. ${ }^{35-37}$ It is remarkable to think that Simpson, at that time 85 years of age, was promptly answering email inquiries, publishing in the neurosurgical scientific literature, and sending packages abroad to interact with a colleague. These correspondences encouraged Chicoine to learn more about Professor Simpson.

In neurosurgery, we are connected to our past, perhaps even more strongly than in other fields, given that neurosurgery is such a small community. The accomplishments of these previous generations have paved the way for all advancements that are being made in neurosurgery today, and much can be learned from their practice. To that end, one of the coauthors of this manuscript (Ralph Dacey) became acquainted with Joseph Buford Pennybacker, Professor Simpson's early neurosurgery mentor in Oxford. In 1981, while completing a portion of his neurosurgical educational training in England, as many of Professor John Jane's University of Virginia neurosurgery residents did, Dacey had the opportunity in 1982 to visit Pennybacker at his retirement home in Kyles of Bute, Scotland (Fig. 7). Pennybacker was born in Somerset, Kentucky, and had direct family ties to Corinne Dacey (née Mears), Ralph Dacey's wife. Seeking out connections such as these helps to keep alive the memories of our predecessors, such as 


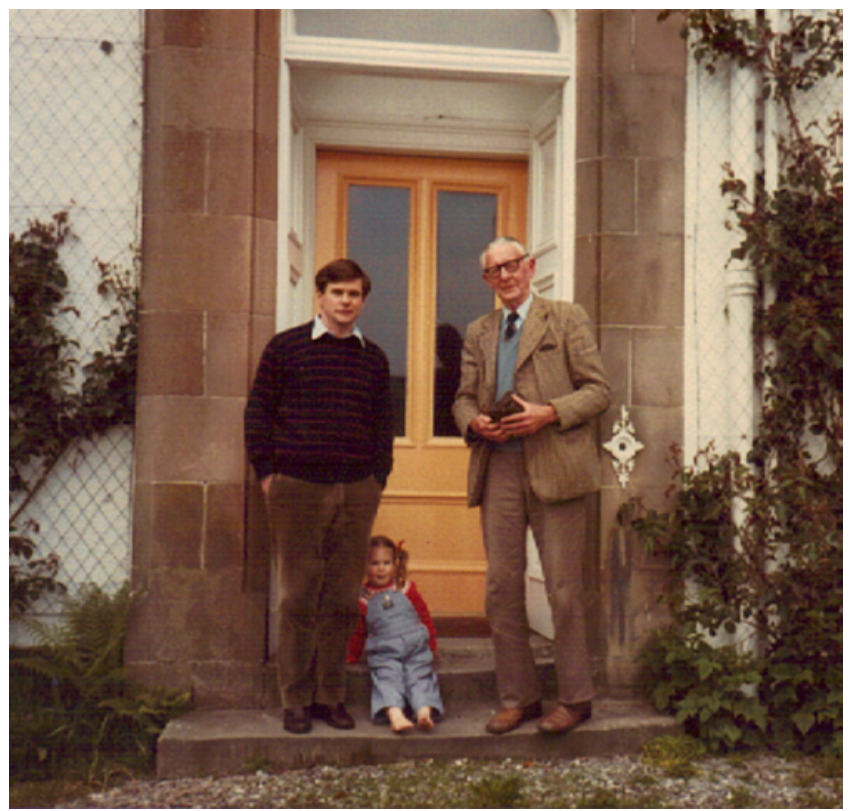

FIG. 7. Ralph G. Dacey Jr. (left) and his daughter Elizabeth with Joseph Buford Pennybacker in 1981 at Pennybacker's retirement home in Kyles of Bute, Scotland. Professor Pennybacker, who was originally from Somerset, Kentucky, honored Cairns' promise to train Simpson in neurosurgery at Oxford. Used with permission of Corinne M. Dacey. Figure is available in color online only.

Professor Simpson and the other historical neurosurgical figures that are part of his story.

\section{Conclusions}

Ever since Harvey Cushing's pioneering work on meningiomas, these tumors have been of great interest to neurosurgeons. Donald Simpson followed in Cushing's footsteps and produced work that significantly impacted the development of surgical strategies for the management of these tumors. All neurosurgeons, no matter their areas of personal expertise, owe a debt to those surgeons who came before them. Every time surgeons enter the operating room they are building on the work of prior generations. Professor Simpson understood this idea to a greater degree than most. He trained with visionary neurosurgical mentors and demonstrated a vested interest in recording and publishing on the history of neurosurgery. ${ }^{38-43}$ In writing this tribute, the authors hope that other neurosurgeons may learn from Professor Simpson's works-both clinical and historical-as well as his views on his profession and the example that he set. Professor Simpson worked tirelessly for patients, his community at large, and global interests, sought to benefit future generations through research, and appreciated the accomplishments of his neurosurgical forebears.

\section{Acknowledgments}

We would like to acknowledge Dr. Peter Reilly and Dr. Amal Abou-Hamden (Department of Neurosurgery, Royal Adelaide Hospital), Dr. Elizabeth Lewis (neurosurgeon, Melbourne, Austra- lia), Dr. Tipu Aziz (Department of Neurosurgery, John Radcliffe Hospital), and the Australian Medical Association (South Australia), as well as Cathy Sarli and Amy Suiter (Bernard Becker Medical Library at Washington University School of Medicine), for their help in acquiring the materials necessary for this manuscript.

Michael Chicoine has received funding from IMRIS Inc. for an unrestricted educational grant to support an iMRI database and outcomes analysis project, the IMRIS Multicenter intraoperative MRI Neurosurgery Database (I-MiND); the Head for the Cure Foundation; and Mrs. Carol Rossfeld and the Alex \& Alice Aboussie Family Charitable Foundation.

\section{References}

1. Simpson D. The recurrence of intracranial meningiomas after surgical treatment. J Neurol Neurosurg Psychiatry. 1957; 20(1):22-39.

2. Spetzler RF, Martin NA. A proposed grading system for arteriovenous malformations. J Neurosurg. 1986;65(4):476-483.

3. Fisher CM, Kistler JP, Davis JM. Relation of cerebral vasospasm to subarachnoid hemorrhage visualized by computerized tomographic scanning. Neurosurgery. 1980;6(1):1-9.

4. A Simpson \& Son Ltd. Today Not Tomorrow: A Century of Progress. Adelaide; 1954.

5. Leading neurosurgeon and medical historian. medicSA. September 2018. Accessed July 17, 2020. https:// amasahistoricalcommittee.files.wordpress.com/2018/09/ simpson_d_a_medicsa_sept_2018.pdf

6. Death of Mr. A.A. Simpson. The Advertiser. November 28, 1939. Accessed July 17, 2020. https://trove.nla.gov.au/ newspaper/article/48852454

7. Lewis E. Professor Donald Simpson: 18 April 1927-22 May 2018, Adelaide South Australia. Childs Nerv Syst. 2019;35: 581-582.

8. Bliss M. Harvey Cushing: A Life in Surgery. Oxford University Press; 2007.

9. Thomson EH. Harvey Cushing: Surgeon, Author, Artist. Neale Watson Academic Publications, Inc; 1981.

10. Stone JL, Patel V, Bailes JE. Sir Hugh Cairns and World War II British advances in head injury management, diffuse brain injury, and concussion: an Oxford tale. J Neurosurg. 2016; 125(5):1301-1314.

11. Hughes JT. Hugh Cairns (1896-1952) and the mobile neurosurgical units of World War II. J Med Biogr. 2004;12(1): $18-24$.

12. Hughes JT. Lawrence of Arabia and Hugh Cairns: crash helmets for motorcyclists. J Med Biogr. 2001;9(4):236-240.

13. Maartens NF, Wills AD, Adams CBT. Lawrence of Arabia, Sir Hugh Cairns, and the origin of motorcycle helmets. Neurosurgery. 2002;50(1):176-180.

14. Tailor J, Handa A. Hugh Cairns and the origin of British neurosurgery. Br J Neurosurg. 2007;21(2):190-196.

15. Walker NM. Hugh Cairns - neurosurgical innovator. $J R$ Army Med Corps. 2008;154(3):146-148.

16. Treason of the Clerks. Australian Ebook Publisher. December 7, 2017. Accessed July 17, 2020. http://www. australianebookpublisher.com.au/publishing/treason-of-theclerks

17. Ponce FA, Lozano AM. Highly cited works in neurosurgery. Part I: the 100 top-cited papers in neurosurgical journals. $J$ Neurosurg. 2010;112(2):223-232.

18. Ponce FA, Lozano AM. Highly cited works in neurosurgery. Part II: the citation classics. J Neurosurg. 2010;112(2):233246.

19. Almutairi O, Albakr A, Al-Habib A, Ajlan A. The top-100 most-cited articles on meningioma. World Neurosurg. 2017; 107:1025-1032.e5.

20. Sughrue ME, Kane AJ, Shangari G, et al. The relevance of 
Simpson Grade I and II resection in modern neurosurgical treatment of World Health Organization Grade I meningiomas. J Neurosurg. 2010;113(5):1029-1035.

21. Nanda A, Bir SC, Maiti TK, et al. Relevance of Simpson grading system and recurrence-free survival after surgery for World Health Organization Grade I meningioma. J Neurosurg. 2017;126(1):201-211.

22. Kinjo T, al-Mefty O, Kanaan I. Grade zero removal of supratentorial convexity meningiomas. Neurosurgery. 1993;33(3): 394-399.

23. Brastianos PK, Horowitz PM, Santagata S, et al. Genomic sequencing of meningiomas identifies oncogenic SMO and AKT1 mutations. Nat Genet. 2013;45(3):285-289.

24. Louis DN, Perry A, Reifenberger G, et al. The 2016 World Health Organization Classification of Tumors of the Central Nervous System: a summary. Acta Neuropathol. 2016;131(6): 803-820.

25. Preusser M, Brastianos PK, Mawrin C. Advances in meningioma genetics: novel therapeutic opportunities. Nat Rev Neurol. 2018;14(2):106-115.

26. Sun SQ, Cai C, Murphy RKJ, et al. Management of atypical cranial meningiomas, part 2: predictors of progression and the role of adjuvant radiation after subtotal resection. Neurosurgery. 2014;75(4):356-363.

27. Sun SQ, Kim AH, Cai C, et al. Management of atypical cranial meningiomas, part 1: predictors of recurrence and the role of adjuvant radiation after gross total resection. Neurosurgery. 2014;75(4):347-355.

28. Simpson DA. The Adelaide kuru team in 1957-1959. Philos Trans R Soc Lond B Biol Sci. 2008;363(1510):3665.

29. Simpson DA, Lander H, Robson HN. Observations on kuru: II. Clinical features. Australas Ann Med. 1959;8(1):8-15.

30. Reilly P. Simpson, Donald Adrian Allen (1927 - 2017). Royal College of Surgeons. Plarr's Lives of the Fellows. Accessed July 17, 2020. https://livesonline.rcseng.ac.uk

31. Simpson D. Obituary: Trevor Alfred Ridley ("Jim”) Dinning CMG, MB, BS, FRCS, FRACS. Med J Aust. 2004;180(4):184

32. Simpson D. Trevor Alfred Ridley Dinning. BMJ. 2003; 327(7425):1230.

33. Simpson D. Helmets in surgical history. Aust N Z J Surg. 1996;66(5):314-324.

34. Former officers \& honorary degree holders of the university. University of Adelaide. Accessed July 17, 2020. https://www. adelaide.edu.au/records/university-archives/online-resources/ former-officers-honorary-degree-holders\#doctors-of-theuniversity-honoris-causa

35. Simpson D. Management of brain abscesses. I: Drainage and antiseptics. J Clin Neurosci. 2013;20(12):1669-1674.

36. Simpson D. Management of brain abscesses. II: Antibiotics and computed tomography. J Clin Neurosci. 2013;20(12): $1675-1681$.

37. Simpson D. Neurosurgery in the age of Cushing: the achievement of Leonard Lindon. ANZ J Surg. 2012;82(5):311-317.
38. Simpson D. From Lanfranc to Sunderland: the surgery of peripheral nerve injuries. ANZ J Surg. 2009;79(12):930-935.

39. Simpson D. Jamieson "Ladye Jayne" temporary vascular clip and applicator (Cushing/Cairns artery forceps). J Clin Neurosci. 2004;11(8):935-936.

40. Simpson D. Phrenology and the neurosciences: contributions of F. J. Gall and J. G. Spurzheim. ANZ J Surg. 2005;75(6): 475-482.

41. Simpson D. Pierre Dionis and the Franco-British dialogue in surgery. ANZ J Surg. 2003;73(5):336-340.

42. Simpson D. The papal anatomist: Eustachius in renaissance Rome. ANZ J Surg. 2011;81(12):905-910.

43. Simpson DA, David DJ. Herbert Moran Memorial Lecture. World War I: the genesis of craniomaxillofacial surgery? ANZ J Surg. 2004;74(1-2):71-77.

\section{Disclosures}

The authors report no conflict of interest concerning the materials or methods used in this study or the findings specified in this paper.

\section{Author Contributions}

Conception and design: all authors. Acquisition of data: all authors. Analysis and interpretation of data: all authors. Drafting the article: all authors. Critically revising the article: all authors. Reviewed submitted version of manuscript: all authors. Approved the final version of the manuscript on behalf of all authors: Chicoine. Administrative/technical/material support: Chicoine, Dacey. Study supervision: Chicoine, Dacey.

\section{Supplemental Information}

Online-Only Content

Supplemental material is available with the online version of the article.

Supplemental Documents 1 and 2. https://thejns.org/doi/suppl/ 10.3171/2020.6.JNS201331.

\section{Previous Presentations}

This work was presented in part by Drs. Chicoine and Dacey as "A tribute to the late Professor Donald Simpson, a Southern neurosurgeon (Southern hemisphere, that is), and author of the 'Simpson grading' for extent of meningioma resection" at the Annual Meeting of the Southern Neurosurgical Society, Scottsdale, AZ, February 29, 2020.

\section{Correspondence}

Michael R. Chicoine: Washington University School of Medicine, St. Louis, MO. chicoinem@wustl.edu. 